\title{
Development of a Culture-ripened Semi-hard Kishk-cheese Containing Bourghol or Semolina
}

\author{
Elham Hajj ${ }^{1}$, Rita Yaacoub ${ }^{2}$, Nadine Al-Arja ${ }^{2}$, Samir Scandar $^{2} \&$ Hussein Dib ${ }^{2}$ \\ ${ }^{1}$ Department of Animal Sciences, Faculty of Agricultural Engineering and Veterinary Medicine, Lebanese \\ University, Dekwaneh, Mount, Lebanon \\ ${ }^{2}$ Department of Food Technology, Faculty of Agricultural Engineering and Veterinary Medicine, Lebanese \\ University, Dekwaneh, Mount, Lebanon \\ Correspondence: Elham Hajj, Faculty of Agricultural Engineering and Veterinary Medicine, Lebanese University, \\ Dekwaneh, Mount, Lebanon. Tel: 961-1370-2419. E-mail: ehajj@ul.edu.lb
}

Received: November 12, 2018

Accepted: November 30, 2018

Online Published: December 24, 2018

doi:10.5539/jfr.v8n1p21

URL: https://doi.org/10.5539/jfr.v8n1p21

\begin{abstract}
In order to develop a new Kishk-based ripened semi-hard cheese, two different wheat types, namely Bourghol and Semolina, were used. The process involved adding together cereal, goat strained yogurt, starter cultures and rennin enzyme. Physicochemical parameters and sensory attributes were assessed during 4 weeks of ripening at $10^{\circ} \mathrm{C}$. The results showed an increase in titratable acidity, $\mathrm{pH}$ and solubility index in both types of cheese over ripening period reaching final levels of $1.95 \%, 3.75$ and $85 \%$ respectively. Free amino acids were accumulating in Semolina cheese $(17.75 \mathrm{mg}$ Leu/g in final product), with a sharp increase after week 2 concurring with a marked decrease in residual lactose. A higher depletion rate of residual lactose was observed for Semolina cheese (49\% in Semolina vs $40 \%$ in Bourghol) (p<0.05), reflecting better utilization of lactose by LAB. Both types of cheese showed limited oxidation rates (low peroxide and TBARS values) and balanced lipolysis, where FFA formed by the latter decreased after week 2. Texture analysis showed that Kishk-cheese made using Bourghol was always harder $(\mathrm{p}<0.05)$ than that of Semolina. Sensory analysis showed that cheese obtained from Bourghol tends to be more yellowish, harder with closed and crumbly body, together with a grainy texture in mouth and pronounced cereal flavor, whereas cheese obtained from Semolina tends to be sour, creamy with a sticky and cohesive texture, and rich lactic, buttery and cheesy flavors. Hedonic tests showed a significant difference $(\mathrm{p}<0.05)$ in preference between both types of cheese where Semolina was always preferred except for odor.
\end{abstract}

Keywords: Bourghol, kishk-cheese, physico-chemical analysis, semolina, sensory analysis

\section{Introduction}

Kishk, a popular component of the Middle Eastern diet, is a traditional dairy product that has been rurally produced for many years ago. Its methods of production have been passed through successive generations and its contribution to the household economy and food security in Lebanese families is undeniable despite the informal marketing and distribution channels. Traditionally, Kishk is made out of Bourghol (parboiled cracked durum wheat) and Laban (fermented milk). The mixture is left to ferment at ambient temperature for 4-8 days, sun-dried to $8-12 \%$ moisture content and finally milled to a fine powder.

Several studies described the physicochemical, nutritional, microbiological and sensory characteristics of traditionally-made Kishk (Tamime \& O’Connor, 1995 ; Muir, Tamime \& Hunter, 1995). Others focused on the texture and viscosity of Kishk products (Abu-Jdayil et al., 2000), rheological properties of the Kishk powder (Salameh et al., 2016) and the substitution of Bourghol with oat, whole wheatmeal, wheat flour, chickpeas, freekeh and other cereals to enhance Kishk nutritional properties (Tamime, Muir, Ashley \& Barclay, 2000; Nassar, shamsia \& Attia, 2016). In particular, oat-based Kishk was a good dietary source of $\beta$-glucan, fibers and unsaturated fatty acids (Tamime, Muir, Barclay, Khaskheli \& McNulty, 1997), whereas using whole wheatmeal enhanced the availability of $\mathrm{Ca}, \mathrm{Fe}, \mathrm{Mg}$ and $\mathrm{Zn}$ (Toufeili, Melki, Shadarevian \& Robinson, 1998).

Although the product is highly nutritious, it still has limited market diversification and access opportunities, hence leaving room for new product development. In a previous study, the addition of all dairy solids in a single step gave a better product with higher acceptability (submitted paper). 
Further, this research was designed to elaborate a new type of ripened semi-hard cheese, based on Kishk production using rennet and starter culture. Besides, and in an attempt to produce a highly-flavored cheese with unique textural properties, substitution of Bourghol with Semolina was also investigated. Since Bourghol is rich in insoluble dietary fiber and gelatinized starch, its substitution with white coarse Semolina (processed from the endosperm, source of soluble fiber and protein) would induce properties changes in the final product. Consequently, a softer curd of cheese may be expected based on the partial increase in protein solubility and the formation of protein colloids with water (Scott, 1986). A comprehensive sensory profiling was finally established for this new product as well as hedonic tests in order to apprehend consumer preferences regarding the two proposed versions of Kishk-cheese.

\section{Material and Methods}

\subsection{Material}

The ingredients used in Kishk-cheese production were purchased from local markets in Lebanon. Commercial white extra-coarse Bourghol, white course Semolina, full fat yogurt made from whole goat's milk $(87 \%$ dry matter, $3.9 \%$ fat), strained yogurt made from whole goat's milk (50\% dry matter, $11.9 \%$ fat), full fat UHT milk and coarse salt were used. Standard cheese-making rennet (Chr. Hansen 147015) and freeze-dried thermophilic yoghurt culture (Chr. Hansen YC-180) were obtained from Chr. Hansen.

\subsection{Manufacturing Process of Kishk-cheese}

A preliminary experiment was carried out in order to calculate the necessary amount of rennet to be added and the accurate milk/yoghurt ratio to obtain the desired coagulum strength within the fortified mix. The assessment of coagulation power of rennet was done by measuring titratable acidity and using taste and visual judgment every $30 \mathrm{~min}$ of incubation (for 3 hours at $\left.35^{\circ} \mathrm{C}\right)$. According to the results, a volume of $0.6 \mathrm{ml}$ of rennet $(0.2 \%$ rennet solution) was finally chosen to be added to $100 \mathrm{~mL}$ of a mixture milk/yogurt $(10 \mathrm{~mL} / 90 \mathrm{~g})$.

The initial pre-mix, formed by mixing milk with Laban and rennet solution, was incubated at $35^{\circ} \mathrm{C}$ for 3 hours then divided into two equal parts. The first one was mixed with Bourghol (B) and the second with Semolina (S) in a ratio of dairy to cereal equal to $1: 1$. On the second day, the two mixtures were kneaded using meat mincing machine, then goat Labneh (premix to Labneh ratio of 1:3) and $2 \%$ of coarse salt were added to each. The dough was further kneaded, formed into balls of $50 \mathrm{~g}$, which were packed and sealed in PE using a vacuum sealer. The balls were left to ripen at $10^{\circ} \mathrm{C}$ in wine cooler for 4 weeks (Figure 1). A batch equivalent to $0.5 \mathrm{~kg}$ of Bourghol and $0.5 \mathrm{~kg}$ of Semolina was prepared.



Figure 1. Flow diagram of the Kishk-cheese manufacturing and analysis 


\subsection{Chemical and Physical Analysis}

Samples were taken on a weekly basis starting from day zero of cheese preparation till week four of cheese maturation. Two independent duplicates for each type of Kishk-cheese were prepared and subjected simultaneously to the same maturation conditions. Results are therefore expressed as the mean of duplicates.

Moisture content was determined using the oven method according to the Association of Official Analytical Chemists (AOAC, 1996). Water activity (Aw) was measured using a water activity meter (HYGROPALM Retronic, 60830142). Determination of total nitrogen (TN) content was performed using Kjeldahl method (Jones, 1991). A conversion factor equal to 6.26, derived from those for dairy (6.38) and cereals (5.7), was adopted.

Fat content was determined according to the Van Gulik method (ISO 3432, 2008), and fat extraction using Bligh and Dyer (1959) method. Acid value of the extracted fat was determined as described by ISO 660 (1983), whereas peroxide value was adapted from that of Al-Fatlawi and Abbas (2010). Thiobarbituric Acid Reactive Substances (TBARS) values were determined using the method described by Bostoglou et al. (1994).

Titratable acidity (TA) was performed according to the AOAC (1996) and $\mathrm{pH}$ measurements were carried out according to Ardö and Polychroniadou (1999) by blending $10 \mathrm{~g}$ of Kishk with $10 \mathrm{ml}$ of distilled water then measuring the $\mathrm{pH}$ using a digital $\mathrm{pH}$ meter (HANNA instruments, modelpH211).

The residual lactose content of Kishk-cheese was determined according to the ISO procedure (5548:2004) for the determination of lactose content in casein/caseinates by photometric method. The results were expressed in $\mathrm{mg}$ anhydrous lactose equivalent per $100 \mathrm{~g}$ of moist cheese.

Amino groups of free amino acids were determined using the cadmium-ninhydrin method allowing rapid monitoring of proteolysis in cheese (Folkertsma \& Fox, 1992). Results were expressed as mg leucine/g of cheese by reference to a standard curve $\left(\mathrm{R}^{2}=0.99\right)$. Solubility Index was determined as described by the American Dry Milk Institute (ADMI 1971). Texture measurements (distance in $\mathrm{mm}$ ) were performed using a penetrometer of Setamatic Stanhope Seta Prolabo 17500-0 equipped with a cylindrical probe of $3.5 \mathrm{~cm}$ diameter and $7.5 \mathrm{~cm}$ length.

\subsection{Microbiological Analysis}

For pre-enrichment, $25 \mathrm{~g}$ of Kishk sample were weighed into a sterile bag and then put into $225 \mathrm{~mL}$ of buffer Ed peptone water. The mixture was homogenized using a Stomacher for 5 minutes, and then incubated at room temperature for $15 \mathrm{~min}$. After homogenization, aliquots of samples were serially diluted, then diluents were spread-plated onto specific agars for the detection and enumeration. These included total aerobic count (ISO 4833-2:2013), Enterobacteria (ISO 21528-2:2004), E. coli (ISO 16649-2: 2001), Salmonella spp. (ISO 6579:2002/Cor 1:2004), Listeria monocytogenes (ISO 11290-1:1996) and sulfite reducing anaerobic bacteria (ISO 15213:2003).

\subsection{Sensory Analysis}

Sensory descriptive analysis of Bourghol and Semolina Kishk-cheeses was conducted using sensory profiling method according to the BS ISO 13299:2003. The freshly produced (week zero) and ripened cheese samples (15 and 30 days-old) were rated by 4 trained panelists for the intensity of specific appearance, odor, flavor, texture and taste attributes (23 descriptors) as well as overall acceptability on a 9-point structured interval scale.

Hedonic tests were carried out on fifty consumers who were asked to respond to a paired preference ballot and to state their overall preference for one of the two products, as well as preference for appearance, odor, texture and taste of the Kishk-cheese.

\subsection{Data Analysis}

One-way ANOVA, Duncan-test, Tukey-test (HSD) and Fisher-test (LSD) were performed on all chemicals and physical results using XLSTAT software (XLSTAT 2016). Student and binomial $\mathrm{p}=1 / 2$ tests were carried out on sensory profiling and preference paired test respectively using Sigma Stat (2012) to detect significant differences. Principal Component Analysis (PCA) was also performed on the matrix of all physico-chemical results using Pearson correlation and Varimax rotation (XLSTAT 2016).

\section{Results and Discussion}

\subsection{Chemical Characteristics}

Kishk-cheese prepared with Bourghol (B) and Semolina (S) had initial moisture content of 48.7\% and 52.7\% respectively. A slight decrease in water content was observed during the four weeks in both B and S, reaching levels of $44.9 \%$ and $47.2 \%$ respectively (Table 1 ). This decrease was favored by addition of starter culture and 
enzyme (rennin) accelerating fermentation which requires water. A significant difference $(\mathrm{p}<0.05)$ was found between B and S regarding water content all over the weeks. Moisture loss was slightly more pronounced in S (10.4\% decrease) than in B cheese (7.8\% decrease). This can be explained by the fact that hydrolysis reactions were confronted to the grains barrier in Bourghol cheese slowing down the hydrolysis reaction. The presence of grains in the initial mixture may act as a physical barrier to enzymatic, mainly rennin and bacterial activities (Cadina \& Robinson, 1979).

The general reduction phenomenon of moisture for both cheeses was in line with the acidity development (Table 1), where an overall increase in titratable acidity (TA), though at different rates, was observed during the ripening period, reaching $1.94 \%$ in $\mathrm{B}$ and $1.80 \%$ in $\mathrm{S}$ at the end of ripening period. Overall, comparable pattern of TA evolution was obtained in the two types of Kishk cheese. It is important to note that the acidity development in Kishk-cheese affects not only the flavor, but also act as inhibitor against a wide range of pathogens and thereby assuring the safety of the final product (Salama, Damir \& Mohamed, 1992).

To the contrary to titratable acidity, $\mathrm{pH}$ increased from 3.6 to 3.77 throughout the maturation period. The $\mathrm{pH}$ evolution pattern is not aligned with the acidity increase, possibly because of the catabolism of lactic acid into weaker acids, or other compounds, that will pick up hydrogen ions and act as buffering agents, together with calcium phosphate. Additionally, proteolysis forms ammonia thus increasing the $\mathrm{pH}$ (Scott, 1968; Johnson, 2002). In other types of cheeses, especially mold ripened, a $\mathrm{pH}$ increase of 0.16 unit in cow's milk shankleesh (a mold-ripened cheese) was recorded after 30 days of ripening (Toufeili, Shadarevian, Artinian \& Tannous, 1995), comparable with the changes reported by Madkor, Shalabi \& Metwalli (1987) in Stilton cheese.

A slight decrease in total proteins (TP) was observed after 2 and 3 weeks of ripening leading to final levels of $12.15 \%$ and $13.96 \%$ in $B$ and $S$ respectively. However, this decrease was not statistically significant $(p>0.05)$ as affected by both types of cheese and fermentation period. Proteolysis of cheese during ripening was studied by measuring free amino acid (FAA) content as an indicator. Nitrogen containing substances, which include free amino acids, mostly occur by the action of rennet, starter culture and to a smaller extent of peptidase from milk (Kalit, Havranek, Kaps, Perko \& Cubric Curik, 2005). FAA content of Semolina-based Kishk-cheese (6.06 mg $\mathrm{Leu} / \mathrm{g})$ increased by threefold at the end of fermentation period $(17.75 \mathrm{mg} \mathrm{Leu} / \mathrm{g})(\mathrm{p}<0.01)$ while it was steady in Bourghol-based one (Table 1). This may be explained by a compensation phenomenon resulting from a balance between FAA accumulation and depletion. The latter may occur through catabolism of FAA into a number of volatile and non-volatile compounds, including ammonia, amines, aldehydes, phenols, indole and alcohols, all of which contribute to cheese flavor (Fox, 2000).

A significant decrease of lactose level was observed throughout the ripening period of Kishk cheese (Table 1), suggesting an efficient utilization of lactose by $\mathrm{LAB}$, hence continuous fermentation. The initial concentration of lactose was $0.70 \mathrm{~g} / 100 \mathrm{~g}$ in $\mathrm{B}$ and $0.62 \mathrm{~g} / 100 \mathrm{~g}$ in $\mathrm{S}$ Kishk cheeses. A faster lactose depletion $(\mathrm{p}<0.05)$, corresponding to $49 \%$, was found in $\mathrm{S}$ cheese, against $40 \%$ in B cheese $(\mathrm{p}<0.05)$. This decrease coinciding with a sharp increase in titratable acidity and free amino acid production, starting week 2 of ripening. These values of lactose depletion were high than those obtained in shankleesh ripening ( $27.81 \%$ decrease) at 30 days (Toufeili et al., 1995).

Table 1. Physicochemical characteristics of Kishk-cheeses produced with Bourghol (B) or Semolina (S) during fermentation at $10^{\circ} \mathrm{C}$ (between week 0 and week 4)

\begin{tabular}{|c|c|c|c|c|c|c|c|c|c|c|}
\hline \multirow[b]{2}{*}{ Weeks } & \multicolumn{5}{|c|}{ Bourghol-based } & \multicolumn{5}{|c|}{ Semolina-based } \\
\hline & 0 & 1 & 2 & 3 & 4 & 0 & 1 & 2 & 3 & 4 \\
\hline Moisture (\%) & $48.75(0.35)$ & $48.30(0.28)$ & $48.01(0.28)$ & $46.80(0.99)$ & $44.97(0.75)$ & $52.71(0.41)$ & $49.90(0.14)$ & $48.61(0.13)$ & $47.95(0.36)$ & $47.20(0.42)$ \\
\hline $\mathrm{pH}$ & $3.61(0.00)$ & $3.70(0.00)$ & $3.69(0.00)$ & $3.75(0.00)$ & $3.77(0.00)$ & $3.60(0.00)$ & $3.66(0.00)$ & $3.65(0.00)$ & $3.74(0.00)$ & $3.74(0.00)$ \\
\hline Titratable acidity $(\%)$ & $0.75(0.01)$ & $1.62(0.12)$ & $1.76(0.06)$ & $2.34(0.50)$ & $1.94(0.06)$ & $1.00(0.02)$ & $1.53(0.38)$ & $1.40(0.06)$ & $1.77(0.46)$ & $1.80(0.12)$ \\
\hline Total proteins (\%) & $18.58(0.33)$ & $20.99(0.70)$ & $30.42(1.51)$ & $11.11(0.03)$ & $12.15(1.16)$ & $18.71(2.85)$ & $19.61(1.87)$ & $26.18(0.65)$ & $22.51(0.74)$ & $13.96(0.94)$ \\
\hline $\begin{array}{l}\text { FAA (mg } \\
\text { Leu equiv/g) }\end{array}$ & $3.44(0.01)$ & $4.03(0.01)$ & $3.02(0.02)$ & $3.36(0.00)$ & $3.90(0.01)$ & $6.06(0.02)$ & $8.20(0.01)$ & $10.38(0.02)$ & $17.31(0.02)$ & $17.75(0.01)$ \\
\hline $\begin{array}{l}\text { Residual lactose } \\
(\mathrm{g} / 100 \mathrm{~g})\end{array}$ & $0.69(0.02)$ & $0.67(0.00)$ & $0.66(0.01)$ & $0.52(0.00)$ & $0.42(0.04)$ & $0.62(0.00)$ & $0.57(0.00)$ & $0.55(0.00)$ & $0.41(0.01)$ & $0.32(0.00)$ \\
\hline Texture $(\mathrm{mm})$ & $2.15(0.21)$ & $2.81(1.67)$ & $3.20(0.14)$ & $3.40(0.42)$ & $2.70(0.13)$ & $17.72(4.26)$ & $16.01(3.23)$ & $10.75(1.77)$ & $10.42(1.52)$ & $9.80(0.70)$ \\
\hline Solubility index (\%) & $70.00(4.24)$ & $87.56(6.15)$ & $65.68(3.54)$ & $88.38(0.81)$ & $84.59(3.258)$ & $72.03(2.73)$ & $88.51(4.08)$ & $70.54(0.60)$ & $83.87(2.07)$ & $84.94(2.39)$ \\
\hline
\end{tabular}

Acid value (AV) refers to hydrolysis of an ester bond by lipase and moisture, producing free fatty acids by the action of enzymes present in the dairy product or of microbiological origin. Changes in AV over weeks was not 
statistically significant and no significant difference was observed between B and S samples. Free fatty acid (FFA) depletion after week 2 may be however explained by interaction of calcium producing Ca soaps of insoluble nature (precipitates) (Fox, 2000), or by their metabolization to other highly flavor compounds, including methyl ketones, lactones and aldehydes (Collins, Sweeney \& Wilkinson, 2003).

As for peroxide value, the bell-shaped trend is typical of peroxide evolution as a function of time during oxidation reactions (Figure 2). Peroxide accumulation due to a progressive increase in peroxide formation occurs until a maximum is reached, followed by peroxide depletion indicating a breakdown into secondary oxidation products (measured as TBARS). The level of peroxidation was always below standard for cheese ( $25 \mathrm{mEq} / \mathrm{kg}$ fat) and therefore cheese products preserved their eating quality. Statistical analysis showed insignificant difference in the peroxide value between the two types of cheese $(\mathrm{p}>0.05)$. As expected, TBARS showed tendency to increase throughout weeks with the highest levels reached at the end of the maturation period ( 0.46 and 0.52 $\mathrm{mEq} \mathrm{MDA} / \mathrm{kg}$ in B and S). These results clearly state that TBARS were accumulating throughout the ripening period as a result of peroxide depletion and transformation into secondary oxidation products. However, these levels are relatively lower or comparable to other studies, where TBARS levels of 2.5 to $3 \mathrm{mg} \mathrm{MDA} / \mathrm{kg}$ were found in fresh buffalo mozzarella cheese (Taticchi et al., 2017) and 0.30 to $0.35 \mathrm{mg} \mathrm{MDA} / \mathrm{L}$ in fresh goat milk (Matak et al., 2007). Therefore, it can be concluded that lipid oxidation was limited during maturation period of Kishk-cheese.
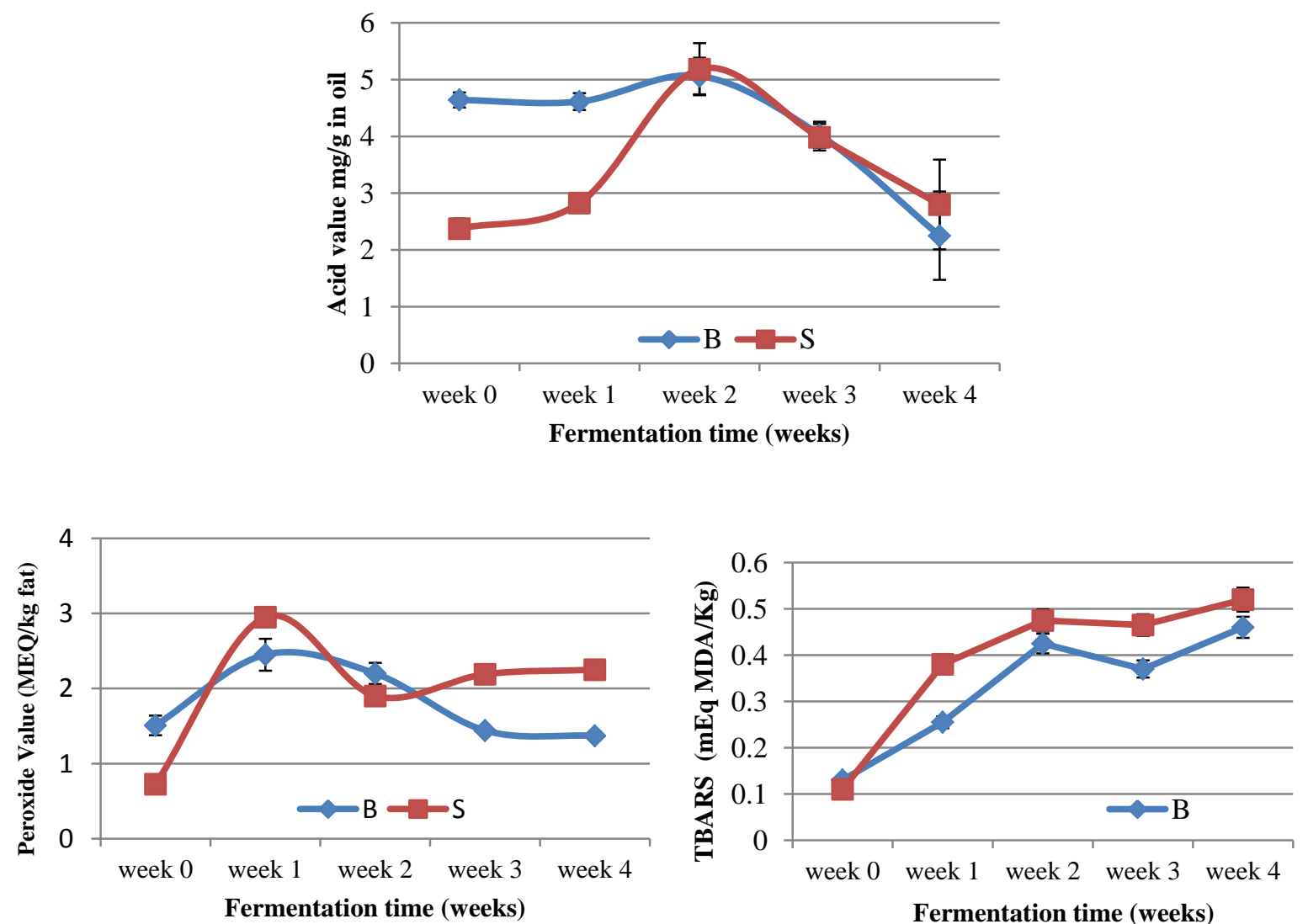

Fermentation time (weeks)

Figure 2. Changes in Acid Value, TBARS and peroxide value of Kishk-cheeses produced using Bourghol (B) and Semolina (S) during fermentation at $10{ }^{\circ} \mathrm{C}$ (data are average of independent duplicates for $B$ and $S$ and error bars are standard deviations)

\subsection{Physical Characteristics}

A significant difference in initial and final body texture was observed between Bourghol and Semolina Kishk-cheeses $(\mathrm{p}<0.05)$. The softer texture of Semolina Kishk (Table 1) can be partly attributed to a higher moisture content as well as a difference in grain structure and rheological behavior. Throughout the ripening period, body texture of $\mathrm{B}$ did not change noticeably in contrast to a general hardening in $\mathrm{S}$ cheese mainly till 
week 2 , followed by a slower change until week $4(\mathrm{p}<0.05)$. This hardening may be attributed to dehydration, and to a degradation of fat which contributes to the body softness, demonstrated by an increase in lipid oxidation. Moreover, the rennet activity added with the starter culture, enhanced clusters formation until a continuous, three dimensional network, which traps water inside, was formed.

The two types of Kishk-cheese showed comparable solubility index values at the beginning and end of the maturation phase (Table 1). This increase mainly occurred during the first week, accounting for around $22 \%$ increase from the initial value, and correlating with a similar sharp increase in titratable acidity.

\subsection{Microbiological Characteristics}

The total aerobic counts of all Kishk-cheeses showed a trend to increase between weeks zero and three of fermentation. Their values were within the range of 6.57 and $6.91 \log _{10} \mathrm{CFU} / \mathrm{g}$, comparable to those obtained by Tamime et al. (2000) (4.64 - $\left.9.11 \log _{10} \mathrm{CFU} / \mathrm{g}\right)$.

Pathogenic bacteria (Enterobacter spp., Salmonella sp., E. coli, sulfite reducing Clostridia, and Listeria monocytogenes) were not detected in Kishk-cheeses during the whole period of fermentation (4 weeks at 9-12 ${ }^{\circ} \mathrm{C}$ ). Major factors responsible for such an absence are hygienic control during manufacture and processing, and high acidity calculated as lactic acid.

\subsection{Sensory Evaluation}

Average sensory profiles for both types of cheeses were developed based on quantitative descriptive analysis (QDA) methodology at weeks 0,2 and 4 (Figure 3). These clearly show an overall organoleptic disparity between the two products. By observing the sensory profiles of S and B final products (week 4), dominant sensory traits can be extracted for each. Cheese obtained from Bourghol tend to be more yellowish, harder with closed and crumbly body, together with grainy texture by mouth and pronounced cereal flavor, whereas cheese obtained from Semolina tend to be sour, creamy with a sticky and cohesive texture, and rich buttery flavor. Some less dominant attributes were also found to be significantly different, including lactic and cheesy odors as well as strained yogurt flavor, which were more pronounced in Semolina cheese. 

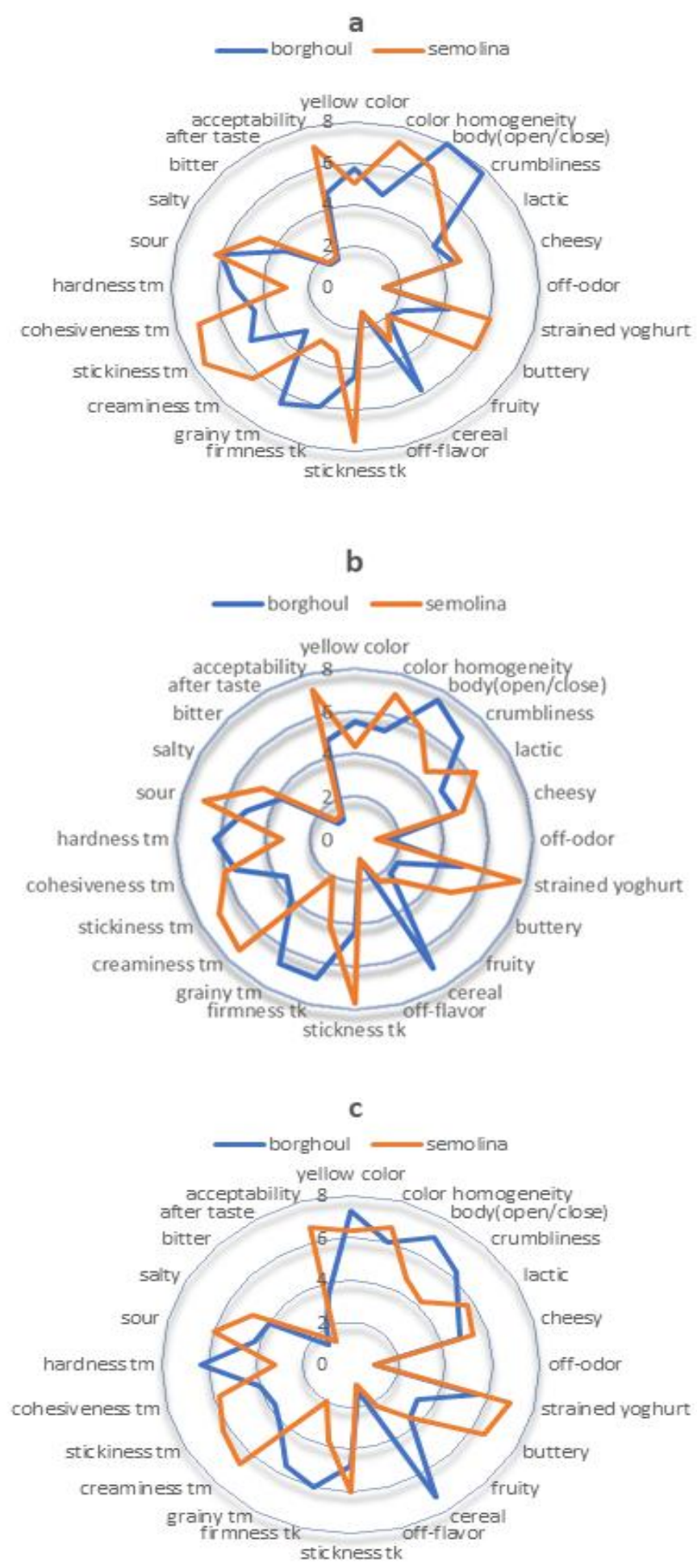

Figure 3. Sensory profiles of Kishk-cheeses produced using Bourghol (B) and Semolina (S) at week 0 (a), week 2 (b) and week 4 (c)

These results are supported by the physico-chemical analysis obtained. A more extensive fermentation observed in Semolina (free amino acids and residual lactose) may have led to a more developed sour taste, lactic odor, fruity, buttery and cheesy flavors. Lipolytic and proteolytic activities produce a myriad of flavor compounds, namely methyl lactones and diacetyl (responsible for the buttery flavor), methyl ketones, $\delta$-lactones, 2-methyl 
butanoic acid and 3-methyl-1-butanol (fruity flavor), thioesters, 3-methyl butanoic acid (cheesy flavor) (Collins et al., 2003; Singh, Drake \& Cadwallader, 2003). A strong negative correlation between hardness (higher in B) and the magnitude of water soluble nitrogen fraction, hence free amino acids, has also been reported in other studies (Bertola, Bevilacqua \& Zaritzky, 1992). The absence of off-flavor and off-odor detection by the panelists may be attributed to low oxidation levels as well as balanced lipolysis as demonstrated by chemical analysis. Bitterness was perceptible for both cheeses, slightly higher for Semolina, which can be explained by proteolysis derived products, especially hydrophobic peptides and free amino acids with bitter note (methionine, phenylalanine and leucine) (Visser, 1993). The major role of rennet in the development of bitterness may be the production of long peptides that will be subsequently degraded to small bitter peptides by starter proteinases (Hassan, Abd-El Gawad \& Enab, 2013). In addition to peptides and amino acids, a number of other compounds can contribute to bitterness in cheese, including amines, amides, substituted amides, long-chain ketones, and some monoglycerides (Singh et al., 2003).

During the ripening period, some characteristics, yellowness, lactic and cheesy odors, strained yoghurt, buttery and fruity flavors, as well as creaminess, increased. Others, such as crumbliness, graininess and stickiness, decreased over time. In conclusion, odor and flavor profiles improved with fermentation time by action of flavor producing LAB. On the other hand, a better physically structured matrix as a result of physical (solubility) and chemical reactions (proteolysis), produced a better texture, especially in Semolina cheese.

Hedonic tests showed a significant difference $(p<0.05)$ in preference (overall and attribute-based) between both types of cheese. Semolina cheese was always prefered by the consumer (overall, appearance, texture and taste), except for odour. This can be explained by the consumer recognition of the typical odor of authentic Kishk in Bourghol cheese.

In order to have a full understanding of the impact of all studied variables on the product, a principal component analysis was carried out on the total variables and samples data matrix. The visual examination of the PCA biplot (axes F1 and F2: 52.46\%) (Figure 4) allowed detection of homogenous clusters, based on both the chronological stage of cheese ripening and the type of cereal. The first factor (F1) allowed separation of the individuals based on the stage of fermentation, where early stages correlated negatively and late stages positively. The second factor (F2) allowed separation of the cheeses based on the cereal used, where Bourghol-based cheeses negatively correlated and Semolina-based positively. The four clusters allowed to separate between the early ripened Bourghol cheeses (cluster 1) and the early ripened Semolina Kishk-cheeses (cluster 2). Late-ripened Semolina cheeses were found in cluster 3 whereas cluster 4 gathered late-ripened Bourghol Kishk-cheeses. Semolina cheeses, however, were generally softer with higher moisture contents and higher FAA values, when compared to Bourghol cheeses. These latter tended to have higher values of residual lactose, with higher acidity and solubility. These results suggest a better fermentation progress reflected by better utilization of lactose and higher proteolysis rates in Semolina, resulting in better quality attributes especially texture. This was confirmed by sensory analysis as discussed earlier. 


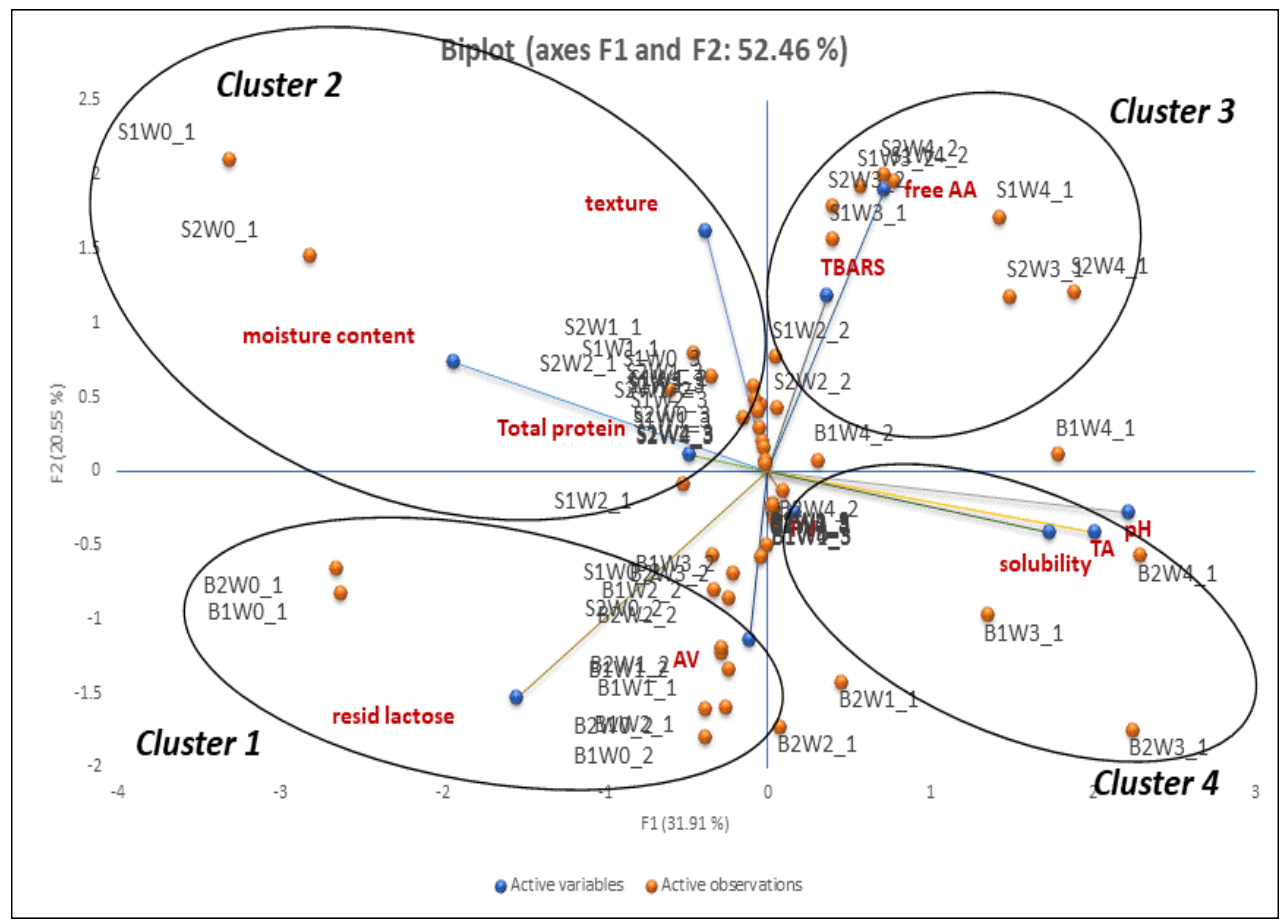

Figure 4. Biplot of the first two principal components

\section{Conclusions}

A comparative experiment was carried out to study the effect of rennet and starter culture on the physicochemical characteristics of fermented Kishk-cheese made using Semolina or Bourghol. It can be concluded that Semolina cheese showed higher rate of hydrolysis reactions, hence fermentation, through the significant decrease of residual lactose, and higher rate of proteolysis through the accumulation of free amino acids (FAA). However, Kishk made using Bourghol was always harder than that of Semolina which had a smoother and creamier body as confirmed by instrumental and sensory analysis of texture.

Sensory properties of the final products were related to cereal composition variation and the progress of biochemical changes during ripening; in fact, Semolina cheese had better organoleptic attributes, demonstrating better visual, flavor and texture attributes. This was also reflected by a higher acceptability by the panelists. Besides, it was always preferred by the consumer in comparison with Bourghol cheese, which was probably downgraded due to inferior flavor and texture attributes.

\section{Acknowledgments}

Authors gratefully acknowledge the financial support of the Lebanese University.

\section{References}

American Dry Milk Institute (ADMI) (1971). Standards for grades of dry milks including methods of analysis, Bulletin 916 (Revised) Chicago: American Dry Milk Institute, Inc.

Al-Fatlawi, A. M. L., \& Abbas, N. M. (2010). Investigation peroxide and acid value in used edible vegetable oil. The Iraqi Journal of Agricultural Sciences, 41(4), 123-132.

AOAC (1996). Association of Analytical Chemists. Acidity of cheese. Titrimetric Method Publication.

Abu-Jdayil, B., Shaker, R., \& Jumah, R. Y. (2000). Rheological behavior of concentrated yoghurt (Labneh). International Journal of Food Properties, 3(2), 207-216. https://doi.org/10.1080/10942910009524628

Ardö, Y., \& Polychroniadou, A. (1999). Laboratory manual for chemical analysis of cheese. Luxembourg: Office for Official Publications of the European Communities, 123pp.

Bertola, N. C., Bevilacqua, A. E., \& Zaritzky, N. E. (1992). Proteolytic and rheological evaluation of maturation of tybo Argentino cheese. Journal of Dairy Science, 75, 3273-3281.

https://doi.org/10.3168/jds.S0022-0302(92)78102-8 
Bligh, E. G., \& Dyer, W. J. (1959). A rapid method for total lipid extraction and purifiction. Can. J. Biochem. Physiol., 37, 911-917. https://doi.org/10.1021/jf00045a019

Bostoglou, N. A., Fletouris, D. J., Papageorgiou, G. E., Vassilopoulos, V., Mantis, A. J., \& Tracktellis, A. (1994). Rapid, sensitive and specific thiobarbituric acid method for measuring lipid peroxidation in animal tissue, food, and feed stuff samples. J. Agric. Food. Chem., 42, 1931-1937. https://doi.org/10.1021/jf00045a019

Cadina, M. A., \& Robinson, R. K. (1979). The acceptability of yoghurt-cereal mixtures to rural community in Mexico. Ecol. Food Nutr., 8, 169-174. http://dx.doi.org/10.1080/03670244.1979.9990563

Collins, Y. F., Mc Sweeney, P. L. H., \& Wilkinson, M. G. (2003). Lipolysis and free fatty acid catabolism in cheese: A review of current knowledge. International Dairy Journal, 13, 841-866. https://doi.org/10.1016/S0958-6946 (03)00109-2

Folkertsma, B., \& Fox, P. F. (1992). Use of Cd-ninhydrin reagent to assess proteolysis in cheese during ripening. Journal of Dairy Research, 59, 217-224. https://doi.org/10.1017/S0022029900030466

Fox, P. F. (2000). Fundamentals of cheese science. Ed. Springer Science \& Business Media, Aspen publishers Inc., $587 \mathrm{pp}$.

Hassan, F. A. M., Abd El- Gawad, M. A. M., \& Enab, A. K. (2013). Flavor Compounds in Cheese (Review). Research on Precision Instrument and Machinery, 2(2), 15-29.

ISO 11290-1 (1996). Microbiology of food and animal feeding stuffs -- Horizontal method for the detection and enumeration of Listeria monocytogenes -- Part 1: Detection method.

ISO 16649-2: (2001). Microbiology of Food and Animal Feeding Stuffs - Horizontal Method for the Enumeration of $\beta$-Glucuronidase-positive Escherichia coli. International Standardization for Organization, Geneva.

ISO 13299: (2003). Sensory analysis - Methodology - General guidance for establishing a sensory profile.

ISO 15213 (2003). Microbiology of food and animal feeding stuffs -- Horizontal method for the enumeration of sulfite-reducing bacteria growing under anaerobic conditions.

ISO 6579:2002/Cor 1 (2004). Microbiology of food and animal feeding stuffs - Horizontal method for the detection of Salmonella spp. and its Corrigendum 1, ISO 6579:2002/Cor. 1:2004.

ISO 5548 (2004). Caseins and caseinates -- Determination of lactose content -- Photometric method.

ISO 21528-2 (2004). Microbiology of food and animal feeding stuffs -- Horizontal methods for the detection and enumeration of Enterobacteriaceae -- Part 2: Colony-count method.

ISO 3432 (2008). Cheese -- Determination of fat content -- Butyrometer for Van Gulik method.

ISO 4833-2 (2013). Microbiology of food and animal feeding stuffs - Horizontal method for the enumeration of microorganisms - Colony-count technique at $30^{\circ} \mathrm{C}$.

Johnson, M. (2002). Cheese pH-What's behind the rise and fall. The Dairy Pipeline, 14(4), 1-12.

Jones, J. B. (1991). Kjeldhal Method for Nitrogen Determination. Athens : GA : Micro-Macro Publishing, pp 79.

Kalit, S., Havranek, J., Kaps, M., Perko, B., \& Cubric Curik, V. (2005). Proteolysis and the optimal ripening time of Tounj cheese. International Dairy Journal, 15, 619-624. https://doi.ord/10.1016/j.idairyj.2004.09.010

Madkor, S., Fox, P. F., Shalabi, S. I. \& Metwalli, N. H. (1987). Studies on the ripening of Stilton cheese: Proteolysis. Food Chemistry, 25, 13-29. https://doi.org/10.1016/0308-8146 (87)90050-1

Matak, K. E., Sumner, S. S., Duncan, S. E., Hovingh, E., Worobo, R. W., Hackney, C. R., \& Pierson, M. D. (2007). Effects of ultraviolet irradiation on chemical and sensory properties of goat milk. Journal of Dairy Science, 90(7), 3178-86. https://doi.org/10.3168/jds.2006-642

Muir, D. D., Tamime, A. Y., \& Hunter, E. A. (1995). Sensory properties of Kishk: comparison of products containing bovine and Caprine milk. International Journal of Dairy Technology, 48(4), 123-127. https://doi.org/10.1111/j.1471-0307.1995.tb02481.x

Nassar, K. S., Shamsia, S. M., \& Attia, I. A. (2016). Improvement of the Nutritional Value of Cereal fermented Milk : 1- Soft Kishk Like., J. Food Process Technol., 7, 1. https://doi.org/10.4172/2157-7110.1000619

Salama, A. A., Damir, A. A., \& Mohamed, M. S. (1992). Effect of cooking on nutrients, microbial and sensory properties of skimmed milk and rayeb Kishk. Faculty of Agriculture, University of Alexandria, Food Science and Technology Department, Alexandria, Egypt. Acta Alim., 21(1), 67-76. 
Salameh, C., Scher, J., Petit, J., Gaiani, C., Hosri, C., \& Banon, S. (2016). Physico-chemical and rheological properties of Lebanese Kishk powder, a dried fermented milk-cereal mixture. Powder Technology, 292, 307-313. https://doi.org/10.1016/j.powtec.2016.01.040

Scott, R. (1986). Cheese making practices. Elsevier Applied Science. London, UK, (pp.71-123).

Singh, T. K., Drake, M. A., \& Cadwallader, K. R. (2003). Flavor of Cheddar Cheese: A Chemical and Sensory Perspective. Comprehensive Reviews in Food Science and Food Safety, 2, 166-189. https://doi.org/10.1111/j.1541-4337.2003.tb00021.x

Tamime, A. Y., \& O'Connor, T. P. (1995). Kishk: a dried fermented Milk/cereal mixture. Int. Dairy J., 5, 109-128. https://doi.org/10.1016/0958-6946(95)92205-I

Tamime A.Y., Muir, D. D., Barclay M. N. I., Khaskheli, M., \& McNulty, D. (1997 a). Laboratory-made Kishk from wheat, oat and barley. 1. Production and comparison of chemical and nutritional composition of Burghol. Food Research International, 30, 311- 317. https://doi.org/10.1016/S0963-9969 (97)00054-9

Tamime, A. Y., Muir, D. D., Barclay, M. N. I., Khaskheli, M., \& McNulty, D. (1997 b). Laboratory-made Kishk from wheat, oat and barley. 2. Compositional quality and sensory properties. Food Research International, 30, 319-326. https://doi.org/10.1016/S0963-9969 (97)00055-0

Tamime, A. Y., Muir, D. D., Ashley, M., \& Barclay, M. N. (2000). Effect of processing conditions and raw material on the properties of Kishk. 1.Compositional and microbiological qualities. Lebensm.-Wiss. U-Technol., 33, 444-451.

Taticchi, A., Bartocci, S., Servili, M., Di Giovanni, S., Pauselli, M., Mourvaki, E., Meo Zilio, D., \& Terramoccia, S. (2017). Effect on quanti-quality milk and mozzarella cheese characteristics with further increasing the level of dried stoned olive pomace in diet for lactating buffalo. Asian-Australas J Anim Sci., 30(11), 1605-1611. https://doi.org/10.5713/ajas.16.0767

Toufeili, I., Melki, C., Shadarevian, S., \& Robinson, R. K. (1998). Some nutritional and sensory properties of Bourghol and whole wheat meal Kishk (a fermented milk-wheat mixture). Food Quality and Preference, 10, 9-15.

Toufeili, I., Shadarevian, S., Artinian, T., \& Tannous, R. (1995). Ripening changes and sensory properties of bovine, caprine and ovine shankleesh. International Dairy Journal, 5, 179-189. https://doi.org/10.1016/0958-6946 (95)92209-M

Visser, S. (1993). Proteolytic enzymes and their relationship to cheese ripening and flavor: An overview. Journal of Dairy Science, 76, 329-350. https://doi.org/10.3168/jds.S0022-0302(93)77354-3

\section{Copyrights}

Copyright for this article is retained by the author(s), with first publication rights granted to the journal.

This is an open-access article distributed under the terms and conditions of the Creative Commons Attribution license (http://creativecommons.org/licenses/by/4.0/). 